\title{
Left Atrial Appendage
}

National Cancer Institute

\section{Source}

National Cancer Institute. Left Atrial Appendage. NCI Thesaurus. Code C127643.

The ear-shaped, muscular pouch of the left atrium. 